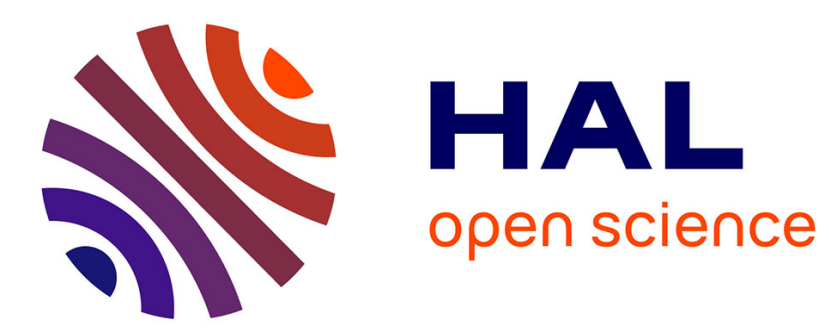

\title{
Should I save or should I not kill? How people solve moral dilemmas depends on which rule is most accessible
}

Ron Broeders, Kees Van den Bos, Patrick A. Müller, Jaap Ham

\section{To cite this version:}

Ron Broeders, Kees Van den Bos, Patrick A. Müller, Jaap Ham. Should I save or should I not kill? How people solve moral dilemmas depends on which rule is most accessible. Journal of Experimental Social Psychology, 2011, 10.1016/j.jesp.2011.03.018 . peer-00995259

\section{HAL Id: peer-00995259 https://hal.science/peer-00995259}

Submitted on 23 May 2014

HAL is a multi-disciplinary open access archive for the deposit and dissemination of scientific research documents, whether they are published or not. The documents may come from teaching and research institutions in France or abroad, or from public or private research centers.
L'archive ouverte pluridisciplinaire HAL, est destinée au dépôt et à la diffusion de documents scientifiques de niveau recherche, publiés ou non, émanant des établissements d'enseignement et de recherche français ou étrangers, des laboratoires publics ou privés. 


\section{Accepted Manuscript}

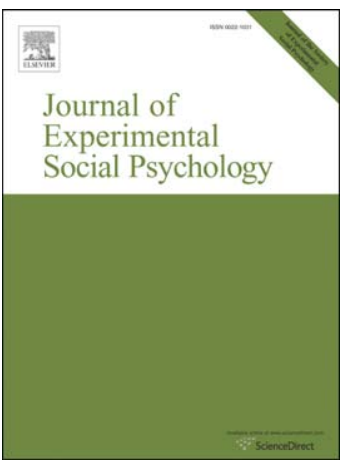

PII:

Reference:

doi: 10.1016/j.jesp.2011.03.018

YJESP 2649

To appear in: Journal of Experimental Social Psychology

Received date: $\quad 12$ November 2009

Revised date: $\quad 17$ March 2011

Accepted date: 21 March 2011

Please cite this article as: Broeders, R., den Bos, K., Müller, P.A. \& Ham, J., Should I save or should I not kill? How people solve moral dilemmas depends on which rule is most accessible, Journal of Experimental Social Psychology (2011), doi: $10.1016 /$ j.jesp.2011.03.018

This is a PDF file of an unedited manuscript that has been accepted for publication. As a service to our customers we are providing this early version of the manuscript. The manuscript will undergo copyediting, typesetting, and review of the resulting proof before it is published in its final form. Please note that during the production process errors may be discovered which could affect the content, and all legal disclaimers that apply to the journal pertain. 
Running head: SHOULD I SAVE OR SHOULD I NOT KILL?

Should I Save or Should I Not Kill?

How People Solve Moral Dilemmas Depends on Which Rule is Most Accessible

Ron Broeders, Kees van den Bos, and Patrick A. Müller

Utrecht University

Jaap Ham

Eindhoven University of Technology

Author Notes:

Ron Broeders, Kees van den Bos, and Patrick Müller, Department of Social Psychology, Utrecht University, The Netherlands; Jaap Ham, Department of HumanTechnology Interaction, Eindhoven University of Technology, The Netherlands.

Ron Broeders is now at the Department of Human-Technology Interaction, Eindhoven University of Technology, The Netherlands. At the moment Patrick A. Müller works for SHL Germany.

We thank Esther Papies, Ruud Custers, and Erik Bijleveld for their helpful comments on an earlier version of this paper. We are especially grateful to Allan Lind for his many thorough comments and suggestions.

This research was supported by a VICI innovational research grant from the Netherlands Organization for Scientific Research (NWO, 453.03.603) awarded to Kees van den Bos. 
Address correspondence to Ron Broeders, School of Innovation Sciences, HumanTechnology Interaction, Eindhoven University of Technology, Den Dolech 2, 5612 AZ, Eindhoven, The Netherlands. Electronic mail may be sent to: r.broeders@tue.nl. 


\begin{abstract}
The literature on how people solve moral dilemmas often focuses on situations in which individuals have to make a decision where different moral rules are in conflict. In some of these situations, such as in footbridge dilemmas, people have to choose between sacrificing a few people in order to save many. The present research focuses on how people decide what to do in dilemmas involving conflicting moral rules. We propose that the rule that is cognitively most accessible during the decision making process (e.g., "Save lives" or "Do not kill") will influence how people solve these moral dilemmas. Three studies are reported that indeed demonstrate that the most accessible rule influences willingness to intervene within footbridge dilemmas. This effect is found even when the accessibility of the rule is induced subliminally.
\end{abstract}




\section{Should I Save or Should I Not Kill?}

How People Solve Moral Dilemmas Depends on Which Rule is Most Accessible Rwanda, Srebrenica, Guantanamo Bay, the nuclear bombing of Hiroshima and Nagasaki, the War on Terror, the Milgram experiment, all are examples of situations in which individuals had to make a decision in the context of conflicting moral rules. In some of these situations decision makers even had to choose between sacrificing a few in order to save many other people. For example, when faced with the massacre in Srebrenica during the Bosnian-Serbian conflict in 1995, United Nations commanders were confronted with the dilemma of sacrificing the life of some (e.g., Serbian soldiers, Dutch military personnel) to save the lives of many Bosnian refugees. Arguably a similar situation arose in the War on Terror. Decision makers are sometimes confronted with a choice between accepting some collateral damage (e.g., lethal casualties amongst innocent civilians) when fighting high-level terrorist leaders in order to prevent terror attacks with potentially hundreds of lethal casualties. Basically, those facing these dilemmas are confronted with the choice between saving many lives at the expense of a few. In other words, people in these dilemmas are faced with deciding between two conflicting moral rules: "Save lives" and "Do not kill". How this conflict is solved is the focus of the present research. More specifically, drawing on methodology from social cognition research we propose that the rule that is cognitively most accessible during the decision making process will most influence how people solve these moral dilemmas, in particular, footbridge dilemmas (Thomson, 1986).

\section{Conflicting Rules}

Saving many at the expense of a few_choosing between the conflicting moral rules "Saving lives" and "Do not kill"- has parallels with the controversy between two opposite philosophical frameworks: utilitarianism and deontology (Beauchamp, 2001). Utilitarianism and deontology judge the moral status of acts using different perspectives (Bartels, 2008), 
often leading to tension and conflict (Greene, 2007; Greene, Nystrom, Engell, Darley, \& Cohen, 2004; Hauser, 2006).

Utilitarianism states that the right act is the one producing the greatest outcome for the greatest number of people. In this perspective, the appropriateness of an action is determined by the positive or negative value of consequences of acts taken, rather than by the acts that led to them (Mill, 1861/1998). Utilitarian moral judgments are aimed at maximizing benefits and minimizing costs for affected individuals by taking into account everybody's interest.

Utilitarian choices lead, by definition, to the greater good. In the moral dilemmas mentioned at the beginning of this paper, this means counting the number of lives saved by each alternative decision and choosing the alternative that produces the best overall outcome (Bartels, 2008), the alternative that results in the most lives saved.

In contrast, deontology is a moral framework stating that there is a set of moral duties or obligations that people must honor regardless of the consequences. From a deontological perspective one must examine whether specific features of actions satisfy certain moral rules. Thus, deontological principles constrain action, in that some acts are prohibited, even when those actions would result in a better outcome for a greater number of people (Bartels, 2008). Regarding the moral dilemmas mentioned at the beginning of this paper, this often means one is not allowed to sacrifice a few lives in order to save many more (Darwall, 2003; Davis, 1993). From a deontological perspective the satisfaction of rights and duties are viewed as more important than are utilitarian considerations (Kant, 1785/1959). In the present paper, we are inspired by the broader philosophical theories about utilitarianism and deontology, but empirically and conceptually we restrict ourselves to a more focused examination of the influence of two rules that may impact people's reactions to footbridge dilemmas (Greene, 2007; Greene et al., 2004; Thomson, 1986). 
In the footbridge dilemma, people are asked to imagine standing next to another person on a footbridge that spans a railroad track. A runaway trolley is headed for five people who will not be able to leave the railroad track in time to avoid being overrun and killed by the trolley. The person facing the dilemma can prevent this from happening, but the only possibility to save the five persons is to push the one person off the footbridge onto the track below. The trolley will crash into this person who as a result will die, but the person's body will slow down and stop the trolley before it reaches the five others on the track.

Thus, in the footbridge dilemma the choice is between saving five persons at the expense of killing one person or letting five die and one survive (Greene, 2007; Greene, Sommerville, Nystrom, Darley, \& Cohen, 2001; Hauser, 2006). Decisions based on utilitarianism would be in favor of pushing the person from the footbridge, thereby maximizing the total utility for all affected individuals (Greene, Morelli, Lowenberg, Nystrom, \& Cohen, 2008; Ham \& Van den Bos, 2010). Following this, one could argue that deciding to choose the alternative that results in the most lives saved corresponds to a rule prescribing "Save lives" (as many as you can) (Bartels, 2008; Boroditsky \& Prinz, 2008; Greene, 2007, 2009; Hauser, 2006; Ritov \& Baron, 1999; Waldmann \& Dieterich, 2007). On the other hand, a deontological solution to the footbridge dilemma would regard pushing the person from the footbridge as an unacceptable violation of rights and duties (Greene et al., 2008; Ham \& Van den Bos, 2010). Therefore, one could argue that the deontological perspective forbids intentionally killing a person (regardless of the consequences) and this prescription can be characterized by the rule "Do not kill” (Bartels, 2008; Boroditsky \& Prinz, 2008; Greene, 2007, 2009; Hauser, 2006; Ritov \& Baron, 1999; Waldmann \& Dieterich, 2007).

So in essence in footbridge dilemmas people have to choose between two different and opposing rules (see also Greene et al., 2004; Kurtines, 1986; Monin, Pizarro, \& Beer, 2007a, 
2007b). Consequently, choosing to act for the greater good means breaking the moral duty not to kill a person, and vice versa. Thus, in the footbridge dilemma the utilitarian and deontological perspective are mutually exclusive because they cannot be satisfied at the same time (Greene et al., 2008; Ham \& Van den Bos, 2010; Tanner, Medin, \& Iliev, 2008; Thomson, 1986), a situation that results in a psychological conflict (Greene, 2007; Greene et al., 2004; Hauser, 2006).

\section{"Saving Lives" or "Not Killing"}

How do people react to and decide what to do in situations where moral rules are in conflict and mutually exclusive? Whereas traditional analyses of moral dilemmas have primarily focused on cognitive or affective explanations (Kohlberg, 1969; Greene \& Haidt, 2002; Greene et al., 2001, 2004), closer inspection of the matter suggests that it also could be that a difference in the cognitive accessibility of either the rule "Save lives" or the rule "Do not kill" influences people's willingness to intervene in footbridge dilemmas. In addition, research suggests that footbridge dilemmas provoke physiological processes linked to uncertainty (Greene et al., 2004).

Recent fMRI research by Greene and colleagues $(2001,2004)$ suggests that when individuals are confronted with footbridge dilemmas, there is a tension between cognitive and social-emotional processes at the neural level. The authors interpret this tension as a conflict between utilitarian and deontological perspectives (Greene et al., 2004). That is, based on the Greene and colleagues (2004) findings one could argue that when solving the footbridge dilemma both the rule "Save lives" and the rule "Do not kill" are often cognitively accessible. When the trolley comes hurtling down the track and the focus is on the five persons, the rule of "Save lives" might be more accessible. But when the focus switches towards the one person and one realizes that the only option to save the five persons is to kill the one person, then the rule "Do not kill" might well become more accessible. The assumption made by 
Greene and colleagues (2004) is based on correlational fMRI data, which cannot demonstrate a causal relationship between the activation of different rules and the effect of activation on the solution of the dilemmas. In other words, although this issue has been fiercely debated and the importance of manipulating the accessibility of utilitarian (e.g., "Save lives") and deontological (e.g., "Do not kill”) rules has been acknowledged (Bartels, 2008; Tanner, Medin, \& Iliev, 2008; Waterman, 1988) previous research has not yet examined systematically the issue of accessibility.

Furthermore, the research by Greene and colleagues has found that the anterior cingulate cortex (ACC), a brain region associated with cognitive conflict (Botvinick, Braver, Barch, Carter, \& Cohen, 2001), shows increased activity when people have to answer footbridge dilemmas, reflecting presumed conflict between cognitive and social-emotional processes when answering these dilemmas. Activation of the ACC has also been related to people's management of their feelings of uncertainty (McGregor, Zanna, Holmes, \& Spencer, 2001; Van den Bos, 2009; Van den Bos, Ham, Lind, Simonis, Van Essen, \& Rijpkema, 2008). Put differently, when people have to solve footbridge dilemmas they may well experience feelings of uncertainty: "What should I do here?" In light of this possibility, it is very interesting to consider that research in the tradition of social cognition has shown that judgments and decisions with a high degree of uncertainty and ambiguity sometimes depend on knowledge accessible to the perceiver at the time of responding (e.g., Bruner, 1957; Higgins, 1996; Higgins \& Bargh, 1987; Kay, Wheeler, Bargh, \& Ross, 2004; Srull \& Wyer, 1986).

As a result of the uncertainty and ambiguity accompanying footbridge dilemmas, we propose that the moral rule that is most accessible during the decision making process ("Save lives" or "Do not kill") will influence how people solve these dilemmas. Taking a contextsensitive perspective towards the accessibility of moral rules and moral cognitions, we argue 
that which moral rule is most accessible will then influence which alternative action is more likely to be pursued in footbridge dilemmas. Paralleling research in social cognition (Bargh, 1997; Bargh \& Chartrand, 1999), we hypothesize that environmental priming may lead to differential accessibility of specific rules at any given time. When the environment or context enhances the accessibility of the rule "save as many people as possible," the "save lives" rule will be relatively more accessible than the "do not kill" rule and individuals will perceive the dilemma as a saving lives problem. They will be more likely to pursue the "saving" course of action at the expense of the "do not kill" course of action, and they will save the five people at the expense of one. On the other hand, when the "Do not kill" rule is made more accessible, this rule will dominate the conflict and individuals will perceive the dilemma as a problem that is about not actively killing. This will trigger the pursuit of this course of action at the expense of "saving" and individuals will refrain from saving five people at the cost of one.

This line of reasoning corresponds to recent work stating that a different focus of attention can have a profound influence on how people perceive moral dilemmas and subsequently react to them (Bartels, 2008; Bartels \& Medin, 2007; Waldmann \& Dieterich, 2007). For example, Bartels (2008) found that when moral dilemmas direct people's attention to violations of moral rules, deontological reactions exert a stronger influence on judgments than when people's attention is directed to the consequences of action. After measuring individual differences in thinking style (intuitive versus deliberative) and manipulating the vividness (making the scenario more affect laden) and catastrophy (expanding the number of net savings) of moral dilemmas, Bartels (2008) found that moral rules play an important, but context sensitive, role in moral cognition. In other words, thinking style and whether the content of the moral dilemma under consideration made moral rules or consequences of action more salient influenced how people solved dilemmas. The current research builds on these findings, but it differs in subtle but important ways from the work by Bartels and others. We 
propose that increasing the accessibility of one rule by means of situational cues can make another rule relatively less accessible, with subsequent influence on the willingness to intervene in moral dilemmas. Put differently, in the current research, instead of measuring individual differences and manipulating the content of moral dilemmas, we prime normative and ethical principles, activating them by meaningful situational cues outside of conscious awareness, and thereby change the process of moral judgment. By doing so, we contribute in several ways to the research literature on moral dilemmas: we provide more solid evidence for the idea that two normative ethical principles govern people's responses in an important theoretical dilemma, and we also demonstrate that priming can influence which moral rule is more likely to be used to solve moral dilemmas.

\section{The Current Research}

The central idea of the current research is that decisions in footbridge dilemmas will be influenced by which rule is most accessible during the decision-making process. Viewing moral rules as knowledge structures or mental representations of appropriate behavior that effortlessly and automatically can guide behavior in certain situations (see e.g., Aarts \& Dijksterhuis, 2003; Schank \& Abelson, 1977), we argue that priming people with either a "Save lives" or a "Do not kill" moral rule should affect willingness to intervene in footbridge dilemmas. More specifically, when individuals are unobtrusively primed with the rule "Save lives" this rule will become more accessible than the rule "Do not kill" and subsequently these individuals will be more willing to save five persons at the expense of one. In contrast, when individuals are primed with the rule "Do not kill" the heightened accessibility of this rule will result in decisions that show less willingness to save five persons at the expense of one person.

The three studies reported here examine the effects of a difference in situational accessibility of one rule or the other on the willingness to intervene in footbridge dilemmas. ${ }^{1}$ 
We manipulated accessibility both supraliminally (Studies 1 and 2) and subliminally (Study 3). To our knowledge, the situational accessibility of normative principles has never been manipulated in moral dilemma research by using priming procedures from social cognition research (see, e.g., Bargh, 1997; Bargh \& Chartrand, 1999; Higgins, 1996). Thus these studies are the first to show that normative rules can be primed outside conscious awareness and that this can change the processes of moral judgment. In this way, the studies reported here provide especially strong evidence for the idea that when conflicting rules are part of moral decision making, the rule that is more accessible, in this case as a result of priming, governs people's responses. In this way we show that how people solve moral dilemmas could be a result of cognitive processes that are put into motion by features of the environment and that operate outside of conscious awareness (Bargh \& Chartrand, 1999).

We tested our hypothesis using two different moral dilemmas: the footbridge dilemma, which has been described above, and the trolley dilemma. In the trolley dilemma, the decision maker is standing beside a switch alongside a railroad track. A runaway trolley is headed for five people who will not be able to leave the railroad track in time to avoid being overrun and killed by the trolley. Participants can prevent this from happening by pulling the switch. However, as a result, the trolley changes to an alternate set of tracks where it will kill one person instead.

Research by Hauser (2006) demonstrates that individuals normally have a greater willingness to intervene in trolley dilemmas (typically 90\% think intervention is acceptable) than in footbridge dilemmas ( $10 \%$ think intervention is acceptable). In other words, the "default" reaction within trolley dilemmas is intervention, whereas the "default" reaction in footbridge dilemmas is inaction. The different tendencies in the two dilemmas might exist because the solution in trolley dilemmas is obvious, so that participants not only approve of intervention more often, but also are faster in answering the question whether intervention is 
appropriate in trolley dilemmas (Greene et al., 2001; Hauser, 2006; Koenigs, Young, Adolphs, Tranel, Cushman, Hauser, et al., 2008). The course of action in trolley dilemmas is so clear that it leaves no room for doubt, causing less likelihood that accessibility differences will affect decision makers in these situations. This line of reasoning is supported by low activation of the ACC when people respond towards trolley dilemmas, in contrast to the heightened activity that is observed when people answer footbridge dilemmas (Greene et al., 2004). Activation of the ACC indicates more tension (Greene et al., 2004), but, more importantly for the current research, also experienced uncertainty (McGregor et al., 2001; Van den Bos, 2009; Van den Bos et al., 2008). The emotional engagement prompted by footbridge dilemmas makes these dilemmas less easy to resolve and more ambiguous with respect to how to respond to the dilemma (Van den Bos, Müller, Beudeker, Cramwinckel, Kumagai, Ruben, et al., 2011), because in footbridge dilemmas the choice is between alternative actions with good motives for both actions (e.g., Greene, 2007; Greene et al., 2001; Hauser, 2006). Put differently, footbridge dilemmas do not allow participants to give a definite answer because alternative and discrepant interpretations are possible, leading to moral incompatibilities and therefore to the uncertain and ambiguous nature of moral issues involved (Van den Bos, 2010). Individuals confronted with footbridge dilemmas are torn between the consequences of taking action by intervening ("saving") and not taking action (“not killing”) (Haidt \& Björklund, 2008; Hauser, 2006; Monin et al., 2007b). This reveals itself in slower reaction times when participants are asked for their willingness to intervene within footbridge dilemmas (Greene, 2009; Greene et al., 2008; Greene et al., 2004; Greene et al., 2001; Hauser, 2006; Koenigs et al., 2008; Monin et al., 2007b). In footbridge dilemmas people have to choose between incompatible cognitions and options, and this leads to feelings of uncertainty and ambiguity (Van den Bos, 2009), as indicated by a higher activation of the ACC among other things. This further supports our idea that in footbridge dilemmas 
participants may be in doubt what to do (Greene et al., 2001; Hauser, 2006; Van den Bos, 2010; Van den Bos et al., 2011) and, according to social cognition research, this would imply that they will be more affected by accessible subtle situational information (see, e.g., Higgins, 1996). The studies to be presented in this paper will examine whether this prediction has merit. We therefore expected that individuals in the footbridge dilemma primed with the rule "Save lives" will have a greater willingness to intervene, compared to individuals primed with "Do not kill". We expect the effects of priming these rules to be much less pronounced in the trolley dilemma.

\section{Study 1}

Study 1 was a field experiment in which participants were primed with either the "Save lives" or "Do not kill" rule by means of two open-ended questions that asked participants to think about either rule.

\section{Method}

Participants and design. Ninety-five individuals (52 men, 43 women) participated in the experiment. ${ }^{2}$ Participants were randomly assigned to one of the conditions of a 2 (primed rule: "Save lives" vs. "Do not kill”) x 2 (dilemma: footbridge vs. trolley) factorial design. Mean age of the participants was 30 years and 4 months $(S D=11$ years, 8 months; range $15-$ 58 years).

Experimental procedure. People travelling by public transport were invited to participate in the experiment. The cover story told participants that we were interested in how people think about rules and following orders. They were asked to read one version of a short story about a peacekeeping mission in Congo, Africa. The different primes were introduced by different versions of the story. The story regarding the "Saving lives" prime was as follows: 
During missions abroad soldiers have to apply to certain rules. This is called a mandate. During a conflict in 1994 in Congo, Africa, the mandate of the UN peace keeping force present in the country was to use armed violence to end the conflict. As a result of several warnings beforehand and during the conflict by the UN-commander in chief on the spot, the Canadian lieutenant-general Roméo Dallaire, UN-soldiers were allowed to conduct offensive actions. They were both allowed to use their weapons to protect the civilian population, as well as when they themselves were attacked. The mandate was based on the principle "Save lives."

For the "Do not kill" version participants read:

During missions abroad soldiers have to apply to certain rules. This is called a mandate. During a conflict in 1994 in Congo, Africa, the mandate of the UN peace keeping force present in the country was not to use any armed violence to end the conflict. Despite several warnings beforehand and during the conflict by the UNcommander in chief on the spot, the Canadian lieutenant-general Roméo Dallaire, UN-soldiers were not allowed to conduct any offensive actions. They were only allowed to use their weapons when they themselves were attacked. The mandate was based on the principle "Do not kill."

After reading the story, participants were asked two open-ended questions. First, participants were asked to put themselves in the position of the lieutenant-general and were asked to write down how they would act in line with either the "Saving lives" or the "Do not kill" mandate. Secondly, participants were asked to think about and write down what the specific rule, either "Saving lives" or "Do not kill", meant for them in their daily lives.

Subsequently, participants were asked to rate how they felt at the moment on the 20 items of the PANAS $(1=$ not at all, $8=$ very strongly $)$. The PANAS was included as a filler task, as well as to determine whether the primes triggered any unwanted positive or negative 
affective reaction. The PANAS consists of two subsets of items, one measuring positive (e.g., “excitement”) and one measuring negative (e.g., "guilt") affect (Watson, Clark, \& Tellegen, 1988). Both subscales were averaged to form reliable scales ( $\alpha$ 's $=.82$ and .84 , respectively). The PANAS was followed by asking participants to read and respond to either the footbridge or the trolley dilemma. The footbridge dilemma was described in the following way to our participants:

You are standing on a footbridge crossing a railroad track. While you are standing next to a stranger, suddenly a runaway trolley comes hurtling down the railroad track.

Further down the railroad track five people are working and they cannot possibly leave the railroad track in time. If the trolley proceeds on its present course it will crash into the five railroad workers and they will be killed in a fatal accident. The only way to save the five people is to push this man off the bridge and into the path of the trolley. The body of this person will break the speed of the trolley as a result of this the trolley will stop and the five persons will survive. The person thrown from the footbridge will certainly die.

The trolley dilemma was described by the following text:

You are standing besides the switch of a railroad track. Suddenly a runaway trolley comes hurtling down the tracks. Further-on down the railroad track five people are working and they cannot possibly leave the railroad track in time. If the trolley proceeds on its present course it will crash into the five railroad workers and they will be killed in a fatal accident. You can save these five people by diverting the trolley onto a different set of railroad tracks. The different railroad track has only one person on it, into which the trolley will crash. This person will be killed as a result of this. After reading the dilemma participants in all conditions were asked the following questions about whether they would intervene in the dilemma: "To what extent do you feel obliged to 
save the five persons on the track at the cost of the one person?", "To what extent do you feel called upon to save the five persons?", "To what extent do you have the feeling to save the five persons on the track?", "To what extent do you feel encouraged to save the five persons on the track?", "To what extent do you feel moved to save the five persons on the track?", "To what extent do you have the urge to sacrifice the one person in order to save the five others?", "Do you think it is acceptable to sacrifice the one person in order to save the five others?", "Do you think it is reasonable to sacrifice the one person in order to save the five persons?", “To what extent do you feel inhibited to sacrifice the one person to save the five others?", "Do you feel restrained to save the five persons?", "Do you feel inhibited to save the five persons on the railroad track at the cost of one?" $(1=$ certainly not, $7=$ certainly $)$. After recoding the last three questions, all items were averaged to form a reliable scale indicating the willingness to intervene in the dilemma $(\alpha=.82)$.

Finally, a funneled debriefing procedure modeled after the procedure used by Chartrand and Bargh (1996) probed participants for awareness or suspicion concerning our priming manipulation. Participants were asked what they thought the purpose of the experiment had been, what they thought the experiment tried to study, whether the story about the peacekeeping force in Africa and subsequently answering the two open-ended questions was related to answering the dilemma and whether they had noticed something special regarding the research. None of the participants indicated any suspicion about the purpose of the experiment, nor did relate the story about the peacekeeping force and its mandate to the decision making task. Finally, participants were thanked for their participation and debriefed. Results

PANAS. To investigate the effects of our manipulations on the positive and negative subscale scores of the PANAS, we submitted both scores to a $2 \times 2$ univariate analysis of variance (ANOVA). These analyses did not find any effects, all $F$ ' $s<1$. This suggests that 
difference in affective states cannot explain the findings reported here. Overall means of the positive and negative subsets were $3.14(S D=0.95)$ and $1.95(S D=0.81)$, respectively.

Willingness to intervene. The scale reflecting participants' willingness to intervene in the dilemma was submitted to a 2 x 2 ANOVA. The analyses yielded a main effect of dilemma, $F(1,93)=36.61, p<.001, \eta^{2}=.27$, and a significant main effect of prime, $F(1,93)$ $=4.56, p<.04, \eta^{2}=.03$. In support of our hypothesis we found the predicted interaction effect, $F(1,93)=4.15, p<.05, \eta^{2}=.03$. More specifically, when responding to the footbridge dilemma, participants who had thought about the rule "Save lives" were more willing to intervene in the dilemma $(M=4.05, S D=1.03)$ than participants who had thought about the rule "Do not kill" $(M=3.31, S D=.89), F(1,93)=5.95, p<.02, \eta^{2}=.06$ (see Figure 1$)$. When responding to the trolley dilemma, there was no significant difference in willingness to intervene between participants who thought about the rule "Save lives" $(M=4.76, S D=.86)$ and participants who had thought about the rule "Do not kill", $(M=4.74, S D=.63), F<1$.

Thus, as predicted, the results of Study 1 demonstrate that individuals confronted with the footbridge dilemma and primed with the rule "Save lives" have a greater willingness to intervene in the dilemma than those primed with "Do not kill". For individuals confronted with the trolley dilemma no differences in willingness to intervene were found between conditions that primed participants with one rule or the other. One potential shortcoming of Study 1 may be that the "Save" version of the short story about the mission in Congo refers to "offensive actions" and the permissibility of using weapons. One could argue that mentioning this might do more than just stress saving but also may have licensed aggression. Furthermore, mentioning the rules of "Save lives" and "Do not kill" in the context of the United Nations can communicate something about the importance of these two moral rules, subsequently leading to demand characteristics. These potential shortcomings were eliminated in Studies 2 and 3 of this paper. 
Study 2

Study 2 was designed to address the potential shortcomings and replicate the results of Study 1 by using more subtle primes. In addition, because we also wanted to know which rule (either "Save lives" or "Do not kill”) more strongly influences the willingness to intervene in the footbridge dilemma, we included a control condition.

According to Haidt (2001), morality concerns more complex social stimuli than the straightforward words and visual items used in research on automaticity. In other words, people's moral context goes beyond simple words such as "fair" or "moral" flashed subliminally. Therefore, in the current studies we presented different stimulus material than that normally used when priming concepts (e.g., flashing words on a computer screen or using a scrambled-sentence task). In the current set of studies we use stimulus materials that, we think, represent and summarize complex ideas: symbols. Symbols represent complex ideas in an immediate way and make the defining point of an idea immediately salient (Carlston \& Mae, 2007; Greenberg, Porteus, Simon, Pyszczynski, \& Solomon, 1995; Ortner, 1973; Weisbuch-Remington, Mendes, Seery, \& Blasovich, 2005). Symbols communicate ideas and beliefs together with knowledge that is associated with these ideas (Hassin, Ferguson, Shidlovski, \& Gross, 2007), such as the abstract meanings of cultural values (e.g. morality). In other words, symbols have the ability to automatically activate conceptions that are associated with the given object by drawing together important and complex beliefs in an immediate manner (Carlston \& Mae, 2007; Hassin et al., 2007; Weisbuch-Remington et al., 2005). Furthermore, symbols play an important function in human conduct (Hassin et al., 2007) and are able to prime social norms (Joly \& Stapel, 2009).

To find symbols that clearly represented either the rule "Save lives" or "Do not kill" we pre-tested how several symbols were perceived by individuals. This pre-test identified three symbols that were most strongly associated with each rule. ${ }^{3}$ Regarding the rule "Save 
lives" the pre-test pointed to the logo of the Red Cross, the symbol of an ambulance, and an image of a lifebuoy. For the rule of "Do not kill" the symbols most associated with the rule were the peace logo, an image of the Ten Commandments, and the logo of the Dutch organization “Tegen Zinloos Geweld” (Against Senseless Violence). In the control condition we used images of a table, a chair and a wheel of a bicycle.

\section{Method}

Participants and design. One hundred and forty-five students (58 men, 87 women) at Utrecht University participated in the experiment, receiving $€ 6$ or course credits. Participants were randomly assigned to one of the conditions of a 3 (primed principle: "Save lives" vs. “Do not kill” vs. control) x 2 (dilemma: footbridge vs. trolley) factorial design.

Experimental procedure. Participants were invited to the laboratory to participate in several social psychological studies. On arrival at the laboratory, participants were led to separate cubicles, each of which contained a computer with a screen and keyboard. Next to the monitor participants found an envelope containing a questionnaire and a pencil. Participants were told that all instructions were presented on the computer screen. The computers were also used to present the stimulus materials to the participants.

The cover story of the experiment informed participants that we were interested in the influence of left- or right-handedness on visual tasks. Participants were asked to solve sliding puzzles. Each puzzle consisted of eight pieces and one empty spot. An example of a puzzle can be found in Appendix 1. The solutions of the puzzles were the symbols found in the pretest to be associated with either the "Save lives" or "Thou shall not kill" rules. The puzzles could be solved by sliding the pieces one by one until a solution was reached, but not longer than six minutes. Before and after each puzzle, the solution of the puzzle (the unscrambled logo) was briefly shown to participants, without mentioning in print or otherwise the label to 
which the logo referred. During the puzzle tasks the solution was shown in a small frame in the upper right corner of the computer screen.

After the third puzzle, participants were asked to continue with an ostensibly unrelated human decision making task by filling out a questionnaire that they found in the envelope lying besides the computer screen. This questionnaire was the same as in Study 1, including the PANAS and the footbridge or trolley dilemma. Both positive and negative subscales of the PANAS were again averaged to form reliable scales ( $\alpha$ 's $=.85$ and .86 , respectively).

The PANAS was followed by either the trolley dilemma or the footbridge dilemma. To get an indication of the robustness of the findings obtained in Study 1 and 2, the dependent variables were slightly different from those used in Study 1. Specifically, after reading the dilemmas participants were asked the following questions about whether they would intervene in the dilemmas: "To what extent do you have the urge to sacrifice the one person in order to save the five others?", "Do you think it is acceptable to sacrifice the one person in order to save the five others?", "Do you think it is reasonable to sacrifice the one person in order to save the five persons?", "To what extent do you feel inhibited to sacrifice the one person to save the five others?", “Do you feel restrained to save the five persons?", "Do you feel inhibited to save the five persons on the railroad track at the cost of one?" $(1=$ certainly not, $7=$ certainly). All of these items were averaged to form a reliable scale regarding the willingness to intervene $(\alpha=.76)$.

The same funneled debriefing structure was used as in Study 1. Participants were asked what they thought the purpose of the puzzle task had been, whether any of the tasks they performed had been related to each other, and whether they thought their performance on the puzzle task might have affected their performance on the next tasks. None of the participants indicated any suspicion regarding the purpose of the experiment, nor did they 
relate the puzzle-task to the decision making task. Finally, participants were paid, thanked for their participation, and debriefed.

Results

$P A N A S$. To investigate the effects of our manipulations on the positive and negative subscale scores of the PANAS, we submitted both scores to a $3 \times 2$ ANOVA. This analysis yielded a significant interaction on the negative subscale only, $F(2,144)=3.34, p<.04$, all other $p$ 's $>.05$. However, the simple effect analyses concerning the negative subscale showed no significant difference between the different conditions regarding the different primes, $F(1$, $144)=2.43, p>.09$. Overall means for the negative subscale for the trolley and footbridge dilemma were $2.03(S D=0.77)$ and $2.23(S D=0.78)$ respectively.

Willingness to intervene. The scale measuring willingness to intervene in the dilemmas was submitted to a $3 \times 2$ ANOVA with number of puzzles that were solved as a covariate. ${ }^{4}$ This yielded a main effect of dilemma, $F(1,144)=3.97, p<.05, \eta^{2}=.24$, and the predicted interaction effect, $F(1,144)=3.23, p<.05, \eta^{2}=.03$. Simple effect analyses showed that for participants confronted with the footbridge dilemma a significant difference in willingness to intervene was found between the different conditions, $F(1,144)=3.53, p<.04, \eta^{2}=.05$ (see Figure 2). Furthermore, planned comparisons revealed that participants confronted with "Saving lives" symbol puzzles were more willing to intervene in the footbridge dilemma $(M=$ $3.38, S D=1.28)$ than participants confronted with "Do not kill" puzzles $(M=2.72, S D=.94)$, $F(1,138)=8.04, p<.01$. Moreover, participants confronted with "Saving lives" puzzles were more willing to intervene in the footbridge dilemma $(M=3.38, S D=1.28)$ than participants confronted with the control puzzles $(M=2.99, S D=.89), F(1,138)=4.28, p<.05$. Participants in the control condition and participants confronted with "Do not kill" puzzles did not differ in their willingness to intervene, $F<1$. Furthermore, no significant difference in the 
willingness to intervene between the different priming conditions was found for participants who read the trolley dilemma, $F(1,144)=1.89 p>.15, \eta^{2}=.02$.

Thus, the rule of "Save lives" and not the rule of "Do not kill" seems to be responsible for the interaction effect. This is important because several researchers in the moral judgment literature have argued that for the footbridge dilemma "Do not kill" is prepotent (Fischer \& Ravizza, 1992; Greene, 2007; Greene et al., 2004; Greene et al., 2001; Petrinovich \& O’Neill, 1996; Petrinovich, O’Neill, \& Jorgensen, 1993). The results of Study 2, however, demonstrate that participants who are primed with the rule "Save lives" are more willing to intervene in footbridge dilemmas than participants who are primed with the rule "Do not kill" or with neutral control primes, thereby showing that the prepotency of "Do not kill" is less evident. In the General Discussion we return to this finding and the implications it may have for the understanding of the exact nature of the moral decision making process.

\section{Study 3}

The results of Study 2 demonstrate that when participants are primed with the rule "Save lives" they are more willing to intervene in footbridge dilemmas than are participants who are primed with the rule of "Do not kill" or with neutral control primes. Furthermore, the "Save lives" rule seems to drive the effect in footbridge dilemmas. For participants confronted with trolley dilemmas no significant difference in willingness to intervene is found between priming with either "Save lives" or "Do not kill".

In order to exclude the possibility that people had become conscious of the symbols used as primes and that they then adopted a conscious strategy when responding or that they were reacting to demand characteristics, Study 3 tried to replicate the findings of Study 2 by presenting the primes subliminally using a parafoveal priming task. To make sure that the primed stimuli were presented outside of participants' perceptual field and therefore outside their conscious awareness, participants in Study 3 first performed a parafoveal-priming task 
modeled after the task used by Custers and Aarts (2007b). In this procedure, stimuli are presented in the parafoveal field (i.e., outside the most sensitive part of the retina), where information cannot be consciously perceived at short presentation times (for further details, see Chartrand \& Bargh, 1996).

\section{Method}

Participants and design. Ninety-one students (39 males, 52 females) from Utrecht University participated in the experiment, receiving $€ 6$ or course credits. Participants were randomly assigned to one of the conditions of a 2 (prime: "Do not kill" vs. "Saving lives") x 2 (dilemma: trolley vs. footbridge) factorial design.

Experimental procedure. Participants were invited to the laboratory to participate in several social psychological studies. On arrival at the laboratory, participants were led to separate cubicles, each of which contained a computer, with a $100-\mathrm{Hz}$ computer screen and a keyboard. Participants were told that all instructions would be presented on the computer screen. The computers were also used to present the stimulus material.

Participants were told that they would participate in a series of unrelated studies. The cover story informed participants that we were interested in the influence of left- and right handedness on eye-hand coordination when people react on events happening in their environment. We explained to the participants that arrows would appear just above the center of their computer screens. These arrows would be presented very briefly and at unpredictable times. Participants were asked to indicate to which direction an arrow pointed, using the " $\mathrm{z}$ " key to indicate that the arrow pointed left and the " " " key to indicate that the arrow pointed to the right. The rationale for adding this task to a normal parafoveal priming task is that the earlier versions of parafoveal priming tasks sometimes are criticized because it remains possible for participants to consciously perceive the primes if they keep attending to one of the corners of the screen. By adding a task (responding to left or right arrows) that requires 
people to attend to the middle of the screen this possibility is minimized. A fixation point consisting of three X'ses was continuously presented in the center of the screen. Participants were told that because of the unpredictable timing of the appearance of the arrows the best way to detect the direction of the arrows was for them to keep their eyes on the fixation point at all times. Furthermore, participants learned that the arrows would be accompanied by very short flashes that would appear on the screen at unpredictable locations and times. In fact these flashes consisted of the images we used in Study 2.

The images would appear in one of the four corners of the screen. The four corners corresponded with the parafoveal locations on the screen, that is outside people's visual field and therefore outside people's conscious awareness. The images were flashed at one of four parafoveal locations on the screen for $20 \mathrm{~ms}$, immediately followed by a $100-\mathrm{ms}$ masking picture of a blue and white whirlwind. Participants were told that these flashes were used to distract them from their main task, which was to decide which direction the arrows pointed at. The participants were advised not to take notice of the flashes and concentrate on the fixation point to improve the accuracy in deciding which direction the arrows were pointing at. Participants were given 12 practice trials to become familiar with the procedure. The images used during these practice trials were the images used in the control condition in Study 2. In the experimental conditions, the images related to either "Saving lives" or "Do not kill" (see Study 2) were primed randomly on all four parafoveal locations on the screen on 75 trials in total.

Following the paravofeal-priming task, a new and unrelated task started in which participants were asked to fill in a questionnaire that measured how they felt at that moment. This task consisted of the PANAS and was included as a filler task and to determine whether the primes triggered any unwanted positive or negative affective reactions. Both positive and negative subscales were averaged to form reliable scales ( $\alpha$ 's $=.89$ and .92 respectively). 
After the PANAS participants were told that a new and ostensibly unrelated task would be uploaded on the screen. This task introduced either the footbridge or trolley dilemma to our participants. After reading one of the two dilemmas, participants were asked questions about whether they would intervene in the dilemma. The items used were the same items as used in Study 2 and were averaged to form a reliable scale indicating the willingness to intervene $(\alpha=$ .72).

Finally, a funneled debriefing procedure was used to ensure that participants were not aware of the priming stimuli (Chartrand \& Bargh, 1996; Stapel, Koomen, \& Ruys, 2002). Participants were asked what they thought the purpose of the arrow-task had been, whether any of the tasks participants performed had been related to each other, whether they thought their performance on the arrow task might have affected their performance on the next tasks and what they thought the content of the flashes during the arrow task had been. Finally, participants were presented with the specific primes used in the study together with other images. They were told that during the trials one of these images had been presented very briefly (in the flashes) on the screen. Participants were asked to indicate which of the images they thought had been flashed on the screen. More than one image could be chosen. Finally, participants were paid, thanked for their participation, and debriefed.

Although participants reported sometimes having seen flashes on the screen, they also reported they did not take notice of them because the main purpose of the task was to decide in which direction the arrows pointed. As instructed, they kept focusing on the arrows. Furthermore, even though most participants reported having seen the mask (the whirlwind), not one participant identified the specific contents of the specific "Saving lives" and "Do not kill" primes. In addition, none of the participants mentioned thinking that the priming task and the moral dilemma task were related. Therefore, we can safely conclude that the priming stimuli were successfully presented outside of participants' awareness, that the experiment 
was successful in not unveiling its real purpose because participants did not connect the arrow task to the moral dilemmas.

Results

$P A N A S$. To investigate the effects of our manipulations on the positive and negative subscale scores of the PANAS, we submitted both scores to a $2 \times 2$ ANOVA. This analysis did not find any main or interaction effects, all $F_{\mathrm{S}}<1$. This suggests that differences in affective states cannot explain the findings reported here. The overall means of the positive and negative subsets were $4.06(S D=0.96)$ and $2.03(S D=0.95)$, respectively.

Willingness to intervene. Willingness to intervene was submitted to a 2 x 2 ANOVA. This yielded a main effect of dilemma, $F(1,90)=27.26, p<.001, \eta^{2}=.23$, and the predicted interaction effect, $F(1,90)=4.70, p<.04, \eta^{2}=.05$. More specifically, for the footbridge dilemma participants primed with symbols associated with the rule "Save lives" were more willing to intervene in the dilemma $(M=3.88, S D=1.37)$ than were participants primed with symbols associated with the rule "Do not kill" $(M=3.09, S D=1.04), F(1,90)=4.06, p<.05$, $\eta^{2}=.04$ (see Figure 3). In the trolley dilemma condition, no significant difference in willingness to intervene was found between participants primed with symbols associated with the rule "Save lives" $(M=4.59, S D=1.11)$ and participants primed with symbols associated with the rule "Do not kill", $(M=4.82, S D=0.87), F<1$.

Thus, consistent with and extending the results of Studies 1 and 2 the findings of Study 3 demonstrate that individuals confronted with footbridge dilemmas and primed, this time subliminally, with the rule of "Save lives" were more willing to intervene than those primed with the rule of "Do not kill". For individuals confronted with a trolley dilemma no significant difference in willingness to intervene was found between priming with either "Do not kill" or "Save lives". 
Taken together, the findings of the three studies presented here strongly suggest that the rule that is most accessible during the decision making process, either "Save lives" or "Do not kill”, influences how people solve footbridge dilemmas. Study 1 showed that making accessible the rule "Save lives" resulted in a greater willingness to intervene than did making accessible the rule "Do not kill". Study 2 replicates and extends these findings by using symbols that represent the respective moral rules as subtle situational cues. Study 2 demonstrated that when the rule "Save lives" was primed by presenting related symbols supraliminal, individuals in footbridge dilemmas again showed a greater willingness to intervene than when symbols regarding "Do not kill” or neutral symbols were presented.

In Study 3 priming the rule "Save lives" again resulted in a greater willingness to intervene in footbridge dilemmas than did priming the rule "Do not kill", this time by presenting symbols related to the specific rules parafovealy. This suggests that the moral rules studied here can be activated subliminally and could influence the decisions that participants make in moral dilemmas outside their conscious awareness. This might explain why there is often dissociation between moral judgments and the reasoning about these judgments based on explicitly understood rules (Hauser, Cushman, Young, Jin, \& Mikhail et al., 2007). The results of Study 3 suggest that the use of moral rules during the decision making process can be unconscious and that therefore people often cannot verbalize how their decisions are linked to specific rules.

In all three of our studies we found that trolley dilemmas did not yield reliable effects of our priming with either "Do not kill" or "Save lives". This finding corroborates our suggestion that as a consequence of the lack of ambiguity and absence of feelings of uncertainty in trolley dilemmas people are less easily influenced by extraneous information in the trolley situation (Van den Bos et al., 2011). 
In the introduction of the current paper the rule "Save lives" is associated with a deontological perspective while the rule "Do not kill" is associated with a utilitarian perspective on how to respond to moral dilemmas. This being said, we want to emphasize that we do not mean to assert that the rule "Save lives" indeed is related in a straightforward fashion to utilitarianism, or that the rule "Do not kill" is based entirely on deontological morality. We are not insisting that the rules in question necessarily meet all criteria that philosophers would use for categorizing a rule as either deontological or utilitarian. Because in the present paper we are interested in how people solve moral dilemmas in which they have to choose between sacrificing one person in order to save five others, we did not use the conventional philosophical definitions. Taking this into account, we believe that the way the rules "Save lives" and "Do not kill" are operationalized in the specific experimental context of footbridge or trolley dilemmas captures the essential question we want to answer in the current research and thus for the purpose of the present paper is justified.

The main dependent variables we have used in our research are different from those that are typically used in other moral dilemma research. Our dependent variables are quite different from "right/wrong" judgments, or even from a prescriptive judgment of what one should do. The rationale for using the interval-level measures we used in our studies was that we studied effects of rather subtle manipulations. We reasoned that interval-level variables assessing willingness to intervene would be sensitive enough to tap the effects of these subtle manipulations. After all, we anticipated that only one of the four cells would differ: We expected that participants who were primed with the rule of "Save lives" and confronted with the footbridge dilemma would show an effect relative to participants in the other three conditions. Using a dichotomous measure ("right/ wrong") to test this effect might not have constituted a sufficiently sensitive measure of the effects studied here, as there might not have been enough variance on such a measure. For this reason we decided to assess willingness to 
intervene using an interval scale. Admittedly, the items used to measure the willingness to intervene in the current research might arguably have differentially captured "kill" and "save" inclinations. Acknowledging this possibility we tested this idea with factor analyses of the items on each of the three scales measuring the willingness to intervene. None of these three factor analyses provided evidence for two underlying dimensions related to "save" and "kill".

Having said this, we propose that the current findings support of a new perspective on how moral judgments are formed. In addition to perspectives that characterize the way people form moral judgments as "moral reasoning” (e.g., Kohlberg, 1969; Monin et al., 2007a, 2007b; Nichols \& Mallon, 2006; Piaget, 1932/1975; Pizarro \& Bloom, 2003; Turiel, 1983) and as "affective intuitions" (e.g., Haidt, 2001; Kagan, 1984; Wilson, 1993), and supplementing the dual-process perspective (Greene et al., 2001) which argues that both reasoning and affective intuition play crucial roles, the current findings suggest that people also make moral decisions as a result of which rule is most accessible cognitively at the time of deciding. So, perhaps not only conscious deliberation (see the moral reasoning approach), fast affective processes (see the moral intuition approach) or a combination of the two (see the dual-process approach) affect moral judgments, but also which rule is most (unconsciously) accessible when people are making the judgment. This is in line with recent research showing that unconscious processes, such as unconscious thinking, can influence moral decisions (Ham \& Van den Bos, 2010). Future research might do well to more fully explore the implications of this additional perspective on the social psychology of moral judgments.

In addition, we propose that the current findings open up several important avenues of future research if we are to understand the exact nature of the decision making process within moral dilemmas. The findings presented here are a first step in uncovering some new processes underlying decision making in moral dilemmas. The next step is to integrate theories and findings from other fields of research, for example the literature on goals. We 
would argue that activating conflicting rules may be profitably viewed as activating conflicting goals. The morality literature tells us that in moral dilemmas people have to choose between different actions with good motives for each of the actions involved (e.g., Beauchamp, 2001; Greene et al., 2001). Thus, although people in footbridge dilemmas have to choose between "Saving lives" and "Not killing" it can be argued that both are desirable alternatives and therefore people are motivated to pursue both courses of action. This motivational aspect of footbridge dilemmas points towards the activation of competing goals (Förster, Liberman, \& Friedman, 2007). Therefore, recent advances in research on goals seem highly relevant for research on moral decision making.

More specifically, we know from the goal literature that people will pursue a goal when that goal is desirable (Bargh, Gollwitzer, Lee-Chai, Barndollar, \& Troetschel, 2001; Custers \& Aarts, 2005, 2007a). Furthermore, research has shown that for goal pursuit to occur the goal concept has to be accessible (Bargh et al., 2001). Also, research on goals shows that conflicting goals can be activated simultaneously, by means of environmental priming (Kruglanski, et al., 2005), and can compete with each other for mental resources (Bargh \& Gollwitzer, 1994; Bargh \& Barndollar, 1996; Bargh et al. 2001; Kruglanski et al., 2005). When goals are in conflict, increased accessibility for any given focal goal results in this most accessible focal goal having stronger impact on behavior than do other less accessible goals (Aarts, Custers, \& Holland, 2007; Bargh \& Barndollar, 1996; Shah, Friedman, \& Kruglanski, 2002). Our line of reasoning put forward in the introduction of the current research has parallels with the goal perspective, and future research could investigate whether moral dilemmas actually are goal conflict situations.

Taking this line of reasoning a bit further, moral dilemmas could be interpreted as hierarchically ordered goal conflicts in which one must, for example, kill in order to save. Future research building on the findings presented here might explore the implications of 
action identification theory (Vallacher \& Wegner, 1987; Wegner \& Vallacher, 1986) for moral dilemmas. According to action identification theory actions can be identified in many ways, resulting in a hierarchical arrangement of an action's various identities. Lower level representations in this action identification hierarchy convey the means by which the action is performed, whereas higher level representations convey a more general understanding of the action focusing on the ends of the action (Trope \& Liberman, 2003; Vallacher \& Wegner, 1987; Wegner \& Vallacher, 1986). It has been suggested that actions can be presented in terms of superordinate and subordinate goals (Liberman \& Trope, 1998; Trope \& Liberman, 2003). From this perspective of goal hierarchies one could argue that the action of intervention in footbridge dilemmas can be identified at a higher level as 'saving' when one focuses on the ends, for example the greater good. Focusing on the means of intervention at a lower level this action would be identified as "pushing the one person". In other words, because in footbridge dilemmas "Saving lives" is conducive for the greater good, one could argue that this goal is higher in the goal hierarchy than is "Do not kill".

In addition, recent research has demonstrated the association between affect and level of focus. Anxiety facilitates local processing (Derryberry \& Reed, 1998), whereas happiness directs attention to global processing (Basso, Schefft, Ris, \& Dember, 1996; Gasper \& Glore, 2002). A positive mood allows people to distance themselves psychologically from the situation resulting in a broader perspective, seeing the big picture (Bar-Anan, Liberman, \& Trope, 2006; Liberman, Sagristano, \& Trope, 2002; Trope \& Liberman, 2003). From research on footbridge dilemmas we know that negative (Greene et al., 2004, 2001) and positive affect (Valdesolo \& DeSteno, 2006) can play a role when solving this dilemma. Recent research by Valdesolo and DeSteno (2006) demonstrated that participants primed with positive affect were subsequently more willing to intervene in the footbridge dilemma. Positive affect results in a more holistic, global mindset as a result of which people see the bigger picture, which is 
the greater good. In other words, people focus on the goal higher in the hierarchy: "Saving lives". Therefore people are more willing to intervene. Furthermore, Greene (2009) states that the footbridge dilemma elicits a negative emotional response leading to deontological judgments. Put differently, negative affect results in local processing focusing on the concrete situation, in a focus on the here and now. That is it focuses the judgment on the means of stopping the trolley: pushing the person on the footbridge. Therefore the goal of "Not killing" becomes more accessible and people refrain from intervention. Future research that combines insights from the goal literature with theoretical insights on morality could improve our understanding of the processes underlying moral decision making. In this way research on morality could profit greatly from using the goal perspective.

Future research might also investigate another idea stemming from the default response that people have regarding footbridge dilemmas: intervention inertia. Note that the results of Study 2 demonstrate that participants who are primed with the rule of "Save lives" are more willing to intervene in a footbridge dilemma than participants who are primed with the rule of "Do not kill" or with neutral control primes. Our findings suggest that making accessible the rule "Save lives" drives the effect. We think that this seems to suggest that people primed with the rule "Save lives" show less behavioral inhibition. Priming "Save lives" has a positive influence on the willingness to intervene relative to priming with the rule "Do not kill". It seems that participants primed with "Save lives" were more 'activated' to intervene in the footbridge dilemma than participants primed with "Do not kill" or those who were not primed with anything. Although speculative, this line of reasoning is in correspondence with recent research showing that people feel inhibited when they are confronted with moral dilemmas and that lowering this inhibition leads to a greater willingness to intervene in these dilemmas (Broeders, Van den Bos, \& Müller, 2011; Van den Bos, 2010; Van den Bos et al., 2011). In other words, making more accessible the rule "Save 
lives" leads to less behavioral inhibition and therefore a greater willingness to intervene, compared to the rule "Do not kill". Future research would do well to explore more fully the implications of the influence of the concept of inhibition on the social psychology of moral judgments and its implications for uncovering the exact nature of the decision making process.

Future research might also investigate the exact influence of the primes used in the current studies, especially the primes associated with "Saving lives". That is, it can be argued that the "Saving lives" primes used in the current research were a little more action-prone as they may have been behavior primes. More specifically, the ambulance prime that we used is relatively action-prone because an ambulance is a fast car when called for duty; likewise, the buoy prime that we used can be considered action-prone because a buoy is something you throw when helping somebody in need. In contrast, it can be argued that the "Do not kill" primes that we used were relatively less action-prone (e.g., the peace logo). It could thus be argued that the "Saving lives" primes we used invoked a general action/approach tendency. This noted, one can also argue that all participants of Study 2 were primed with action as a result of the puzzle task used in that study in which in all conditions participants were busy with moving pieces of stimulus materials on their computer screens, and in this study we still found a significant difference in willingness to intervene between the "Saving lives" and "Do not kill" primes. Future studies could more thoroughly investigate whether the "Saving lives" primes are more action-prone compared to the "Do not kill" primes.

For future research it might be interesting to connect our findings to prospect theory and gain/loss framings. The classic example of framing effects involves the Asian disease problem, in which participants are told that an outbreak of a disease threatens to kill 600 people (Tversky \& Kahneman, 1981). People are asked to choose between a risky option and a certain option that both have the same expected value. Additionally, this problem is either 
framed in terms of gains (the outcomes are described in terms of the numbers of lives saved) or in terms of losses (in terms of lives lost). The common finding is that people choose the certain option when the problem is framed in terms of gains, but choose the risky option when the problem is framed in terms of losses (for reviews, see Kühberger, 1998; Rothman \& Salovey, 1997). Furthermore, recent research has found that people with protected values (i.e., values that are shielded against a trade-off against any other (economic) value no matter how large the benefits of this trade-off (thus making these values comparable to deontological rules; Baron \& Spranca, 1997) are insensitive to the framing of outcomes (Tanner \& Medin, 2004). Following this, one could argue that people primed with the rule "Do not kill" will not be sensitive to framing effects, whereas people primed with the moral rule of "Saving lives" will be sensitive to framing effects. Future studies could explore the impact of the primes used in the current research with dilemmas and decisions from the judgment and decision making literatures.

\section{Conclusions}

To return to the findings presented here, the current research broadens our insight into how people solve moral dilemmas. Our data suggest that the philosophical frameworks (utilitarianism and deontology) that are assumed to play a role in moral decision making according to the morality literature indeed seem to influence the decision making process within moral dilemmas. At least, rules that are associated with and inspired by these different moral perspectives influence the willingness to intervene in certain moral dilemmas. This influence even can take place outside people's awareness by priming symbols associated with rules related to these frameworks as subtle situational cues. Based on our pre-test and the findings of Studies 1-3 we believe that symbols can activate specific rules, such as "Saving lives" or "Do not kill". Our findings demonstrate that which rule is most accessible during the decision making process subsequently influences the willingness to intervene and the outcome 
of footbridge dilemmas. As a result of priming the rule "Save lives" a utilitarian perspective is more accessible and therefore people are directed towards saving lives and subsequently show a bigger willingness to intervene. In contrast, priming the rule "Do not kill" leads to the default reaction within footbridge dilemmas: intervention inertia.

On a final note, we believe the current research adds a new perspective on how people solve moral dilemmas in which certain rules are in conflict. Apparently the accessibility of any specific rules over and above the accessibility of rival alternative rules can have an impact on how people solve moral dilemmas. This difference in accessibility can be a result of situational cues. We are not saying that pursuing one or the other rule is better or worse. We are only saying that the moral perspective with which individuals enter the decision making process matters. For the people who are the target of the decision making process in moral dilemmas, which moral perspective is activated in those making the decisions arguably matters a lot.

\section{Appendix 1}
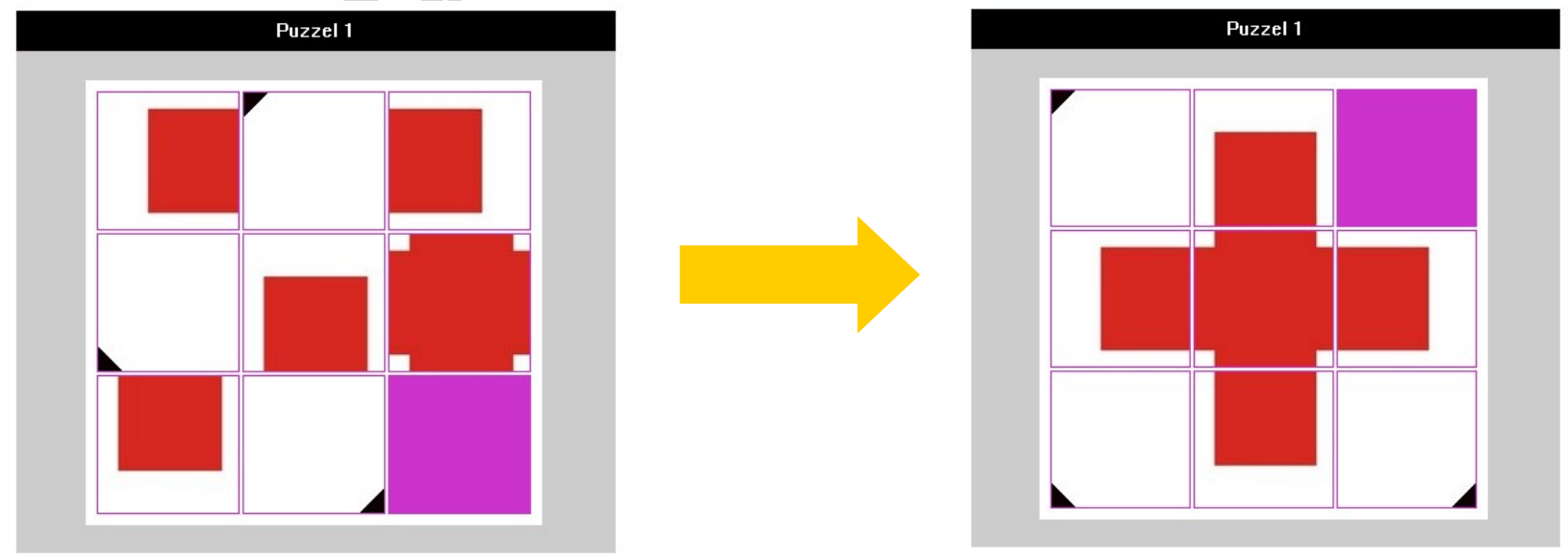

An example of a scrambled version and solution of the symbols used in the sliding puzzle task in Study 2. This example uses the logo of the International Red Cross, and was part of the "Saving lives" manipulation. 


\section{References}

Aarts, H., Custers, R., \& Holland, R. W. (2007). The nonconscious cessation of goal pursuit: When goals and negative affect are coactivated. Journal of Personality and Social Psychology, 92, 165-178.

Aarts, H., \& Dijksterhuis, A. (2003). The silence of the library: Environment, situational norm, and social behavior. Journal of Personality and Social Psychology, 84, 18-28.

Bar-Anan, Y., Liberman, N., \& Trope, Y. (2006). The association between psychological distance and construal level: An implicit association test. Journal of Experimental Psychology: General, 135, 609-22.

Bargh, J. A. (1997). The automaticity of everyday life. In R. S. J. Wyer (Ed.), The automaticity of everyday life: Advances in social cognition (Vol. 10, pp. 1-61). Mahwah, NJ, US: Lawrence Erlbaum Associates, Publishers.

Bargh, J. A., \& Barndollar, K. (1996). Automaticity in action: The unconscious as repository of chronic goals and motives. In P. M. Gollwitzer, \& J. A. Bargh (Eds.), The psychology of action: Linking cognition and motivation to behavior (pp. 457-481). New York, NY: Guilford Press.

Bargh, J. A., \& Chartrand, T. L. (1999). The unbearable automaticity of being. American Psychologist, 54, 462-479.

Bargh, J. A., \& Gollwitzer, P. M. (1994). Environmental control of goal-directed action: Automatic and strategic contingencies between situations and behavior. In W. D. Spaulding (Ed.), Integrative views of motivation, cognition, and emotion. Nebraska symposium on motivation (Vol. 41) (pp. 71-124). Lincoln, NE: University of Nebraska Press.

Bargh, J. A., Gollwitzer, P. M., Lee-Chai, A., Barndollar, K., \& Troetschel, R. (2001). The 
automated will: Nonconscious activation and pursuit of behavioral goals. Journal of Personality and Social Psychology, 81, 1014-1027.

Baron, J., \& Spranca, M. (1997). Protected values. Organizational Behavior and Human Decision Processes, 70, 1-16.

Bartels, D. M. (2008). Principled moral sentiment and the flexibility of moral judgment and decision making. Cognition, 108, 381-417.

Bartels, D. M., \& Medin, D. L. (2007). Are morally-motivated decision makers insensitive to the consequences of their choices? Psychological Science, 18, 24-28.

Basso, M. R., Schefft, B. K., Ris, M. D., \& Dember, W. N. (1996). Mood and global-local visual processing. Journal of the International Neuropsychological Society, 2, 249255.

Beauchamp, T. L. (2001). Philosophical ethics: An introduction to moral philosophy (3rd ed.). Boston: McGraw-Hill.

Boroditsky, L., \& Prinz, J. (2008). What thoughts are made of. In G. R. Semin \& E. R. Smith (Eds.), Embodied grounding: Social, cognitive, affective, and neuroscientific approaches (pp. 98-115). Cambridge: Cambridge University Press.

Botvinick, M. M., Braver, T. S., Barch, D. M., Carter, C. S., \& Cohen, J. D. (2001). Conflict monitoring and cognitive control. Psychological Review, 108, 624-652.

Broeders, R., Van den Bos, K., \& Müller, P. A. (2011). Embodied power to the people: Powerful postures decrease the inhibition to intervene in moral and bystander dilemmas. Manuscript submitted for publication.

Bruner, J. S. (1957). On perceptual readiness. Psychological Review, 64, 123-152.

Carlston, D. E., \& Mae, L. (2007). Posing with the flag: Trait-specific effects of symbols on person perception. Journal of Experimental Social Psychology, 43, 241-248. 
Chartrand, T. L., \& Bargh, J. A. (1996). Automatic activation of impression formation and memorization goals: Nonconscious goal priming reproduces effects of explicit task instructions. Journal of Personality and Social Psychology, 71, 464-478.

Cushman, F., Young, L., \& Hauser, M. (2006). The role of conscious reasoning and intuition in moral judgment: Testing three principles of harm. Psychological Science, 17, 10821089.

Custers, R., \& Aarts, H. (2005). Positive affect as implicit motivator: On the nonconscious operation of behavioral goals. Journal of Personality and Social Psychology, 89, 129142.

Custers, R., \& Aarts, H. (2007a). In search of the nonconscious sources of goal pursuit: Accessibility and positive affective valence of the goal state. Journal of Experimental Social Psychology, 43, 312-318.

Custers, R., \& Aarts, H. (2007b). Goal-discrepant situations prime goal-directed actions if goals are temporarily or chronically accessible. Personality and Social Psychology Bulletin, 17, 623-633.

Darwall, S. (2003). Deontology. Oxford: Oxford University Press.

Davis, N. (1993). Contemporary deontology. In P. Singer (Ed.), A companion to ethics (pp. 205-218). Malden, MA: Blackwell Publishing.

Derryberry, D., \& Reed, M. A. (1998). Anxiety and attentional focusing: Trait, state and hemispheric influences. Personality and Individual Differences, 25, 745-761.

Fischer, J. M., \& Ravizza, M. (1992). Ethics: Problems and principles. Fort Worth, TX: Harcourt Brace Jovanovich.

Förster, J., Liberman, N., \& Friedman, R. S. (2007). Seven principles of goal activation: A systematic approach to distinguishing goal priming from priming of non-goal constructs. Personality and Social Psychology Review, 11, 211-233. 
Gasper, K., \& Clore, G. L. (2002). Attending to the big picture: Mood and global versus local processing of visual information. Psychological Science, 13, 34-40.

Greenberg, J., Porteus, J., Simon, L., Pyszczynski, T., \& Solomon, S. (1995). Evidence of a terror management function of cultural icons: The effects of mortality salience on the inappropriate use of cherished cultural symbols. Personality and Social Psychology Bulletin, 21, 1221-1228.

Greene, J. D. (2007). The secret of Kant's soul. In W. Sinnott-Armstrong (Ed.), Moral psychology: The neuroscience of morality: Emotion, disease, and development (Vol. 3, pp 35-117), MIT Press, Cambridge, MA.

Greene, J. D. (2009) Dual-process morality and the personal/impersonal distinction: A reply to McGuire, Langdon, Coltheart, and Mackenzie. Journal of Experimental Social Psychology, 45, 581-584.

Greene, J. D., \& Haidt, J. (2002). How (and where) does moral judgment work? Trends in Cognitive Sciences, 6, 517-523.

Greene, J. D., Morelli, S. A., Lowenberg, K., Nystrom, L. E., Cohen, J. D. (2008) Cognitive load selectively interferes with utilitarian moral judgment. Cognition, 107, 11441154.

Greene, J. D., Nystrom, L. E., Engell, A. D., Darley, J. M., \& Cohen, J. D. (2004). The neural bases of cognitive conflict and control in moral judgment. Neuron, 44, 389-400.

Greene, J. D., Sommerville, R. B., Nystrom, L. E., Darley, J. M., \& Cohen, J. D. (2001). An fMRI investigation of emotional engagement in moral judgment. Science, 293, $2105-$ 2108.

Haidt, J. (2001). The emotional dog and its rational tail: A social intuitionist approach to moral judgment. Psychological Review, 108, 814-834. 
Haidt, J., \& Björklund, F. (2008). Social intuitionists answer six questions about moral psychology. In W. Sinnott-Armstrong (Ed.), Moral psychology, volume 2: The cognitive science of morality: Intuition and diversity (pp. 181-217). Cambridge, MA: MIT Press.

Ham, J., \& Van den Bos, K. (2010). On unconscious morality: The effects of unconscious thinking on moral decision making. Social Cognition, 28, 74-83.

Hassin, R. R., Ferguson, M. J., Shidlovski, D., \& Gross, T. (2007). Subliminal exposure to national flags affects political thought and behavior. Proceedings of the National Academy of Sciences, 104, 19757-19761.

Hauser, M. (2006). Moral minds: How nature designed our universal sense of right and wrong. New York: Ecco.

Hauser, M., Cushman, F., Young, L., Jin, R. K., \& Mikhail, J. (2007). A dissociation between moral judgments and justifications. Mind \& Language, 22, 1-21.

Higgins, E. T. (1996). Knowledge activation: Accessibility, applicability, and salience. In A. Kruglanski \& E. T. Higgins (Eds.), Social psychology: Handbook of basic principles (pp. 133-168). New York: Guilford Press.

Higgins, E. T., \& Bargh, J. A. (1987). Social cognition and social perception. Annual Review of Psychology, 49, 129-134.

Joly, J. F., \& Stapel, D. A. (2009). Staff, miter, book, share: How attributes of Saint Nicholas induce normative behavior. European Journal of Social Psychology, 39, 145-153.

Kagan, J. (1984). The nature of the child. New York: Basic Books.

Kant, I. (1785/1959). Foundation of the metaphysics of morals. Indianapolis: Bobbs-Merill.

Kay, A. C., Wheeler, S. C., Bargh, J. A., \& Ross, L. (2004). Material priming: The influence of mundane physical objects on situational construal and competitive behavioral choice. Organizational Behavior and Human Decision Making Processes, 95, 83-96. 
Koenigs, M., Young, L., Adolphs, R., Tranel, D., Cushman, F., Hauser, M., \& Damasio, A. (2007). Damage to the prefrontal cortex increases utilitarian moral judgments. Nature, $21,1-4$.

Kohlberg, L. (1969). Stage and sequence: The cognitive-developmental approach to socialization. In D. A. Goslin (Ed.), Handbook of socialization theory and research (pp. 347-480). Chicago: Rand McNally.

Kruglanski, A. W., Shah, J., Fishbach, A., Friedman, R., Young Chun, W., \& Sleeth-Keppler, D. (2005). A theory of goal systems. In M. P. Zanna (Ed.), Advances in experimental social psychology (Vol. 34, pp. 331-378): Academic Press.

Kurtines, W. M. (1986). Moral behavior as rule governed behavior: Person and situation effects on moral decision making. Journal of Personality and Social Psychology, 50, 784-791.

Kühberger, A. (1998). Influence of framing on risky decisions: A meta-analysis. Organizational Behavior and Human Decision Processes, 75, 23-55.

Liberman, N., Sagristano, M. D., \& Trope, Y. (2002). The effect of temporal distance on level of mental construal. Journal of Experimental Social Psychology, 38, 523-35.

Liberman, N., \& Trope, Y. (1998). The role of feasibility and desirability considerations in near and distant future decisions: A test of temporal construal theory. Journal of Personality and Social Psychology, 75, 5-18.

McGregor, I., Zanna, M. P., Holmes, J. G., \& Spencer, S. J. (2001). Compensatory conviction in the face of personal uncertainty: Going to extremes and being oneself. Journal of Personality and Social Psychology, 80, 472-488.

Mill, J. S. (1861/1998). Utilitarianism. New York: Oxford University Press.

Monin, B., Pizarro, D., \& Beer, J. (2007a). Deciding vs. reacting: Conceptions of moral judgment and the reason-affect debate. Review of General Psychology, 11, 99-111. 
Monin, B., Pizarro, D. A., \& Beer, J. S. (2007b). Reason and emotion in moral judgment: Different prototypes lead to different theories. In K. D. Vohs \& R. F. Baumeister (Eds.), In K.D. Vohs, R.F. Baumeister, \& G. Loewenstein (Eds.), Do emotions help or hurt decision making? A hedgefoxian perspective (pp. 219-244). New York: Russell Sage.

Nichols, S., \& Mallon, R. (2006). Moral dilemmas and moral rules. Cognition, 100, 530-542.

Ortner, S. B. (1973). On key symbols. American Anthropologist, 75, 1338-1446.

Petrinovich, L., \& O’Neill, P. (1996). Influence of wording and framing effects on moral intuitions. Ethology and Sociobiology, 17, 145-171.

Petrinovich, L., O’Neill, P., \& Jorgensen, M. (1993). An empirical study of moral intuitions: Toward an evolutionary ethics. Journal of Personality and Social Psychology, 64, 467-478.

Piaget, J. (1975). The moral judgment of the child. London: Routledge and Kegan Paul. (Original work published 1932)

Pizarro, D. A., \& Bloom, P. (2003). The intelligence of the moral intuitions: Comment on Haidt (2001). Psychological Review, 110, 193-196.

Ritov, I., \& Baron, J. (1999). Protected values and omission bias. Organizational Behavior and Human Decision Processes, 79, 79-94.

Rothman, A. J., \& Salovey, P. (1997). Shaping perceptions to motivate healthy behavior: The role of message framing. Psychological Bulletin, 121, 3-19.

Schank, R. C., \& Abelson, R. P. (1977). Scripts, plans, goals, and understanding. Hillsdale, NJ: Erlbaum.

Stapel, D. A., Koomen, W., \& Ruys, K. I. (2002). The effects of diffuse and distinct affect. Journal of Personality and Social Psychology, 83, 60-74. 
Srull, T. K., \& Wyer, R. S. (1986). The role of chronic and temporary goals in social information processing. In R. Sorrentino \& E. T. Higgins (Eds.), Handbook of motivation and cognition (pp. 503-549). New York: Guilford.

Tanner, C., \& Medin, D. L. (2004). Protected values: No omission bias and no framing effects. Psychonomic Bulletin and Review, 11, 185-191.

Tanner, C., Medin, D. L., \& Iliev, R. (2008). Influence of deontological versus consequentialist orientations on act choices and framing effects: When principles are more important than consequences. European Journal of Social Psychology, 38, 757769.

Thomson, J. J. (1986). Rights, restitution, and risk. Cambridge, MA: Harvard University Press.

Trope, Y., \& Liberman, N. (2003). Temporal construal. Psychological Review, 110, 403-421.

Turiel, E. (1983). The development of social knowledge: Morality and convention. Cambridge: Cambridge University Press.

Tversky, A., \& Kahneman, D. (1981). The framing of decisions and the psychology of choice. Science, $211,453-458$.

Valdesolo, P., \& DeSteno, D. (2006). Manipulations of emotional context shape moral judgment. Psychological Science, 17, 476-477.

Vallacher, R. R., \& Wegner, D. M. (1987). What do people think they're doing? Action identification and human behavior. Psychological Review, 94, 3-15.

Van den Bos, K. (2009). On the psychology of the uncertain self and the integration of the worldview defense zoo. Psychological Inquiry, 20, 252-261.

Van den Bos, K. (2010). Self-regulation, homeostasis, and behavioral disinhibition in normative judgments. In D. R. Bobocel, A. C. Kay, M. P. Zanna, \& J. M. Olson 
(Eds.), The psychology of justice and legitimacy: The Ontario Symposium (Vol. 11, pp. 205-228). New York: Psychology Press.

Van den Bos, K., Ham, J, Lind, E. A., Simonis, M., Van Essen, W. J., \& Rijpkema, M. (2008). Justice and the human alarm system: The impact of exclamation points and flashing lights on the justice judgment process. Journal of Experimental Social Psychology, 44, 201-219.

Van den Bos, K., Müller, P. A., Beudeker, D. A., Cramwinckel, F. M., Kumagai, T., Ruben, S., Smulders, L., \& Van der Laan, J. (2011). On the role of aggression and power in reactions to moral dilemmas: Implications of a behavioral disinhibition perspective for moral education. Manuscript in preparation.

Waldmann, M. R., \& Dieterich, J. H. (2007). Throwing a bomb on a person versus throwing a person on a bomb. Psychological Science, 18, 247-253.

Waterman, A. S. (1988). On the uses of psychological theory and research in the process of ethical inquiry. Psychological Bulletin, 103, 283-298.

Watson, D., Clark, L. A., \& Tellegen, A. (1988). Development and validation of brief measures of positive and negative affect: The PANAS scales. Journal of Personality and Social Psychology, 54, 1063-1070.

Wegner, D. M., \& Vallacher, R. R. (1986). Action identification. In R. M. Sorrentino \& E. T. Higgins (Eds.), Handbook of motivation and cognition: Foundations of social behavior (pp. 550-582). New York: Guilford.

Weisbuch-Remington, M., Mendes, W. B., Seery, M. D., \& Blascovisch, J. (2005). The nonconscious influence of religious symbols in motivated performance situations. Personality and Social Psychology Bulletin, 31, 1203-1216.

Wilson, J. Q. (1993). The moral sense. New York: Free Press. 


\section{Footnotes}

${ }^{1}$ To obtain an idea of the default reaction in trolley and footbridge dilemmas and whether both rules could play a role when solving the dilemmas, we tested in a pilot study whether the rule "Save lives" or "Do not kill" is more accessible by default in trolley and footbridge dilemmas. After reading either the trolley or footbridge dilemma, participants were asked several unipolar questions about their decision in relation to the rules "Save lives" $(\alpha=$. 90) and "Do not kill" $(\alpha=.79)$. For each rule, participants were asked whether the specific rule was decisive $(1=$ totally not agree, $8=$ totally agree $)$, important $(1=$ totally not important, $8=$ very important $)$ and whether their decision was based on the specific rule $(1=$ certainly not, $8=$ certainly). Furthermore, bipolar items $(\alpha=.94)$ asked participants whether the decision followed from, and was related to one of either rules $(1=$ Do not kill, $8=$ Do save). In addition, participants were asked whether during the decision making process the rule "Do not kill" was more important than the rule "Save lives", and vice versa $(1=$ certainly not, $8=$ certainly). The "Do not kill" scale demonstrates that participants confronted with the footbridge dilemma indicated that their decision was significantly more based on the rule of "Do not kill" $(M=6.18, S D=1.56)$ than was the case with participants who read the trolley dilemma $(M=4.46, S D=1.55), F(1,49)=15.25, p<.001$. Scores on the "Saving lives" scale shows the opposite pattern. Participants confronted with the footbridge dilemma indicated that their decision was significantly less based on the rule of "Saving lives" $(M=3.68, S D=1.80)$ than did participants who read the trolley dilemma $(M=7.25, S D=.66), F(1,49)=86.83, p<$ .001. In addition, the bipolar scale demonstrates that participants in the trolley dilemma based their decision to a significant greater extent on the rule of "Saving lives" $(M=6.77, S D=$. 66), whereas participants in the footbridge dilemma were more influenced by the rule of "Do not kill" $(M=3.14, S D=1.91), F(1,49)=73.72, p<.001$. 
${ }^{2}$ Gender did not interact with the hypothesis of our studies and was dropped from analyses.

${ }^{3}$ Participants were asked questions whether they associated a symbol with either the rule "Save lives" or "Do not kill" ( 1 = totally disagree, $8=$ totally agree $)$. For "Saving lives" the pre-test resulted in the logo of the Red Cross $(M=6.35)$, the symbol of an ambulance $(M$ $=6.82)$ and an image of a lifebuoy $(M=6.83)$. For "Do not kill" this resulted in the peacelogo $(M=4.78)$, an image of the Ten Commandments $(M=5.40)$ and the logo of a Dutch organization called "Tegen Zinloos Geweld” (Against Senseless Violence) which is a ladybird $(M=6.43)$. Furthermore, we asked bi-polar questions in which participants had to indicate which rule they thought the image stood for, and which rule the image was most related to (1 = Do not kill, 8 = Saving lives). The "Saving lives" symbols showed the following results: the Red Cross logo $(M=6.63)$, the ambulance symbol $(M=6.67)$ and the lifebuoy $(M=6.98)$. The results for the "Do not kill" symbols were as follows: peace-logo $(M=3.28)$, the Ten Commandments $(M=3.00)$ and the "Against Senseless Violence" logo $(M=2.73)$. When asked to make a dichotomous choice regarding which image best fitted the moral rule $83 \%$, $85 \%$, and $85 \%$ respectively choose the peace-logo, image of the Ten Commandments and the logo of "Against Senseless Violence" as best fitting the rule of "Do not kill", whereas 100\%, $95 \%$, and $100 \%$ of the respondents respectively choose the logo of the Red Cross, an ambulance and the life-buoy as best fitting the rule of "Saving lives".

${ }^{4}$ To control for the influence of number of puzzles solved, we inserted the number of solved puzzles as a covariate. We did this because we thought that solving puzzles might lead to a qualitatively different cognitive process than when the puzzles are not solved. Participants who actually have solved (all) the puzzles had probably more deeply processed the symbols due to searching for a solution than did participants who failed to come up with a solution. We argue that participants who did not solve (all) the puzzles did not have a keen 
eye on the primes. Although each participant was confronted with the solution of the puzzles, just before, during and after making the puzzles, it could well be that participants solving the puzzles have cognitively visualized the symbols better because they were actively looking for and found a solution. In this way, participants who solved the puzzles could have had an advantage regarding the influence of the subtle primes over participants who did not manage to solve the puzzles. Without controlling for numbers of puzzles solved the most important contrast between the "Saving" and "Not killing" primes regarding the willingness to intervene within the footbridge dilemma condition remained significant, $F(1,139)=6.25, p<.02$. Other effects (the interaction effect and the contrast between the "Saving lives" and "Do not kill" condition) described previously in Study 2 were marginally significant. As noted before, the results indicated no difference between the "Do not kill" and the control condition regarding the willingness to intervene within the footbridge dilemma. 


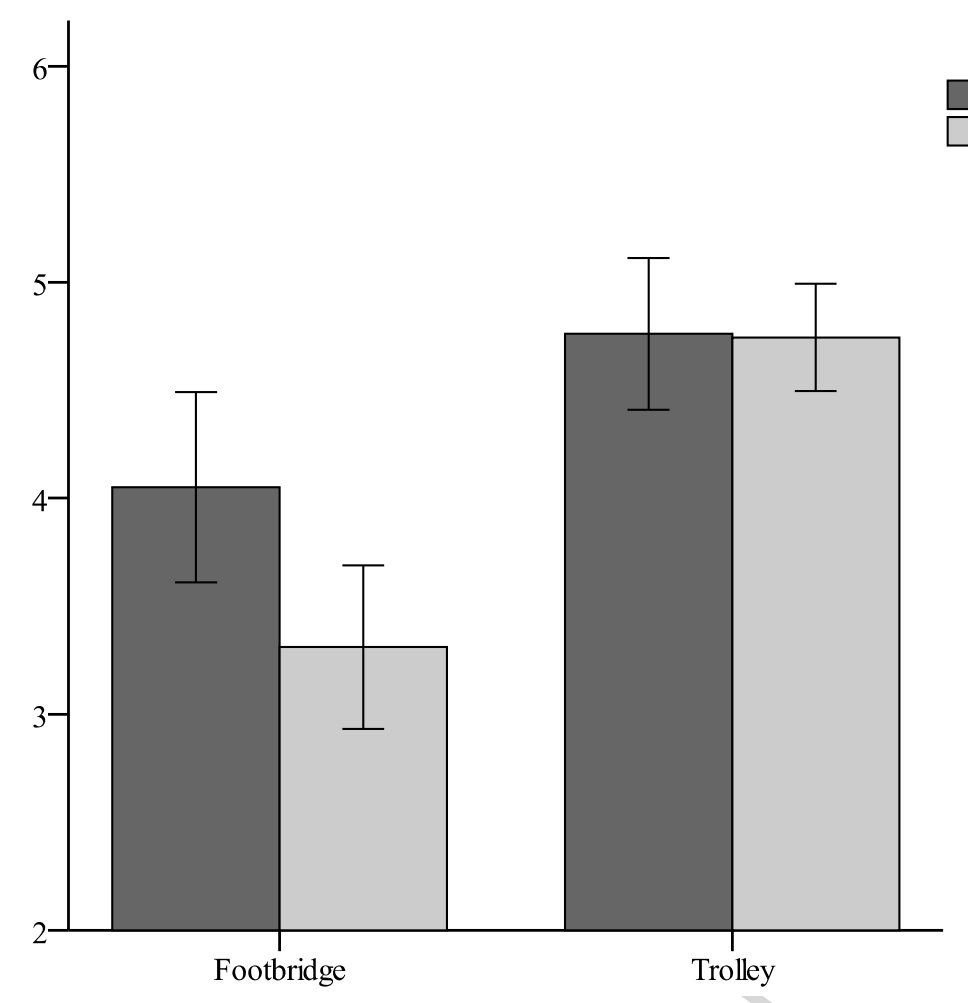

\section{Mandate}

Saving lives

$\square$ Do not kill

Figure 1. Willingness to intervene (on a scale from 1 to 7 ) in footbridge and trolley dilemmas as a function of manipulated accessibility of the rules "Saving lives" and "Do not kill" (Study 1). Higher bars indicate greater willingness to intervene. 


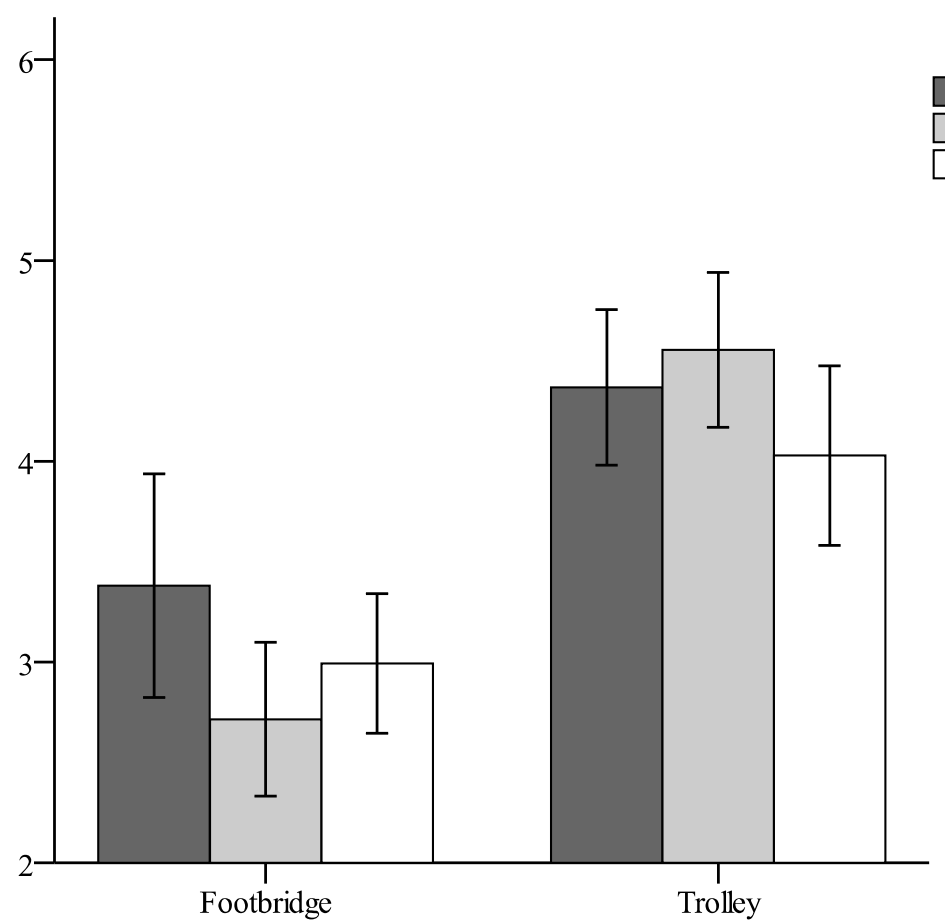

\section{Puzzle}

Saving lives

Do not kill

$\square$ Control

Figure 2. Willingness to intervene (on a scale from 1 to 7 ) in footbridge and trolley dilemmas as a function of supraliminal priming of "Saving lives", "Do not kill", or "Control" symbols (Study 2). Higher bars indicate greater willingness to intervene. 


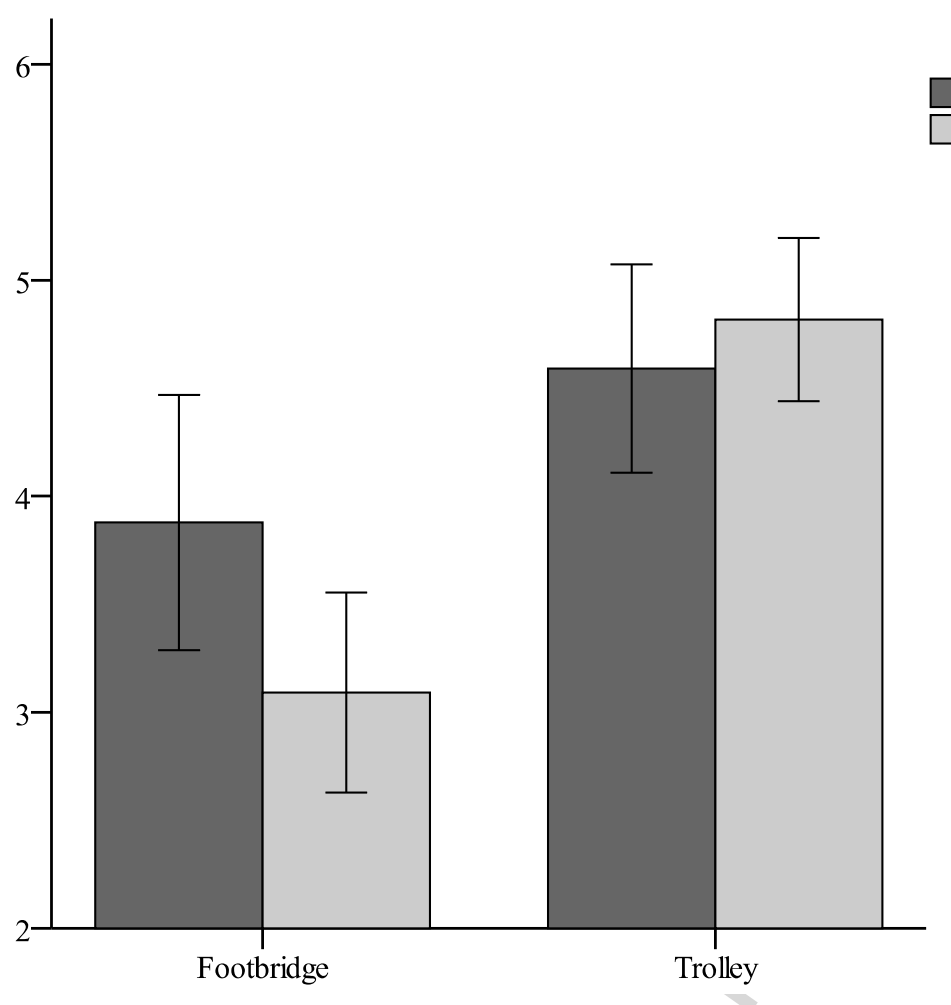

Prime

Saving lives

Do not kill

Figure 3. Willingness to intervene (on a scale from 1 to 7) in footbridge and trolley dilemmas as a function of subliminal priming of "Saving lives" and "Do not kill" symbols (Study 3). Higher bars indicate greater willingness to intervene. 